\title{
REVISED Delayed administration of recombinant plasma gelsolin improves survival in a murine model of severe influenza
}

\section{[version 2; peer review: 2 approved]}

\author{
Zhiping Yang ${ }^{1}$, Alice Bedugnis ${ }^{1}$, Susan Levinson², Mark DiNubile², \\ Thomas Stossel2+, Quan Lu¹, Lester Kobzik (D)1 \\ ${ }^{1}$ Department of Environmental Health, Harvard T.H. Chan School of Public Health, Boston, MA, 02115, USA \\ 2BioAegis Therapeutics, North Brunswick, NJ, 07960, USA \\ + Deceased author
}

\begin{tabular}{l} 
V2 First published: 06 Nov 2019, 8:1860 \\
https://doi.org/10.12688/f1000research.21082.1 \\
Latest published: 21 Feb 2020, 8:1860 \\
https://doi.org/10.12688/f1000research.21082.2 \\
\hline
\end{tabular}

Abstract

Background: Host-derived inflammatory responses contribute to the morbidity and mortality of severe influenza, suggesting that immunomodulatory therapy may improve outcomes. The normally circulating protein, human plasma gelsolin, is available in recombinant form (rhu-pGSN) and has beneficial effects in a variety of pre-clinical models of inflammation and injury.

Methods: We evaluated delayed therapy with subcutaneous rhupGSN initiated 3 to 6 days after intra-nasal viral challenge in a mouse model of influenza A/PR/8/34.

Results: Rhu-pGSN administered starting on day 3 or day 6 increased survival (12-day survival: $62 \%$ vs $39 \%$, pGSN vs vehicle; $p<0.00001$, summary of 18 trials), reduced morbidity, and decreased proinflammatory gene expression.

Conclusions: Rhu-pGSN improves outcomes in a highly lethal influenza model when given after a clinically relevant delay.

Keywords

influenza, pneumonia, plasma gelsolin, immunomodulation, hostdirected

This article is included in the Emerging Diseases and Outbreaks gateway.

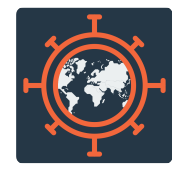

\section{Open Peer Review}

Approval Status

1 2

version 2

(revision)

21 Feb 2020

version 1

06 Nov 2019

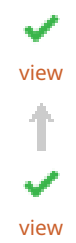

view

1. David H. Dockrell, University of Edinburgh,

Edinburgh, UK

2. David S Fedson, None (retired, prolific writer on influenza and host-directed therapies),

Sergy Haut, France

Any reports and responses or comments on the article can be found at the end of the article. 
Corresponding author: Lester Kobzik (lkobzik@hsph.harvard.edu)

Author roles: Yang Z: Data Curation, Formal Analysis, Investigation, Methodology, Writing - Review \& Editing; Bedugnis A: Investigation, Methodology, Project Administration; Levinson S: Conceptualization, Formal Analysis, Funding Acquisition, Project Administration, Writing - Review \& Editing; DiNubile M: Conceptualization, Formal Analysis, Project Administration, Writing - Review \& Editing; Stossel T: Conceptualization, Formal Analysis, Writing - Review \& Editing; Lu Q: Funding Acquisition, Project Administration, Supervision, Writing - Review \& Editing; Kobzik L: Conceptualization, Data Curation, Formal Analysis, Funding Acquisition, Project Administration, Supervision, Visualization, Writing - Original Draft Preparation, Writing - Review \& Editing

Competing interests: S. Levinson and M. DiNubile are employees and shareholders of BioAegis Therapeutics. T. Stossel is a founder, shareholder and consultant to BioAegis Therapeutics.

Grant information: This work was supported by the National Institutes of Health, grant number AI125152.

The funders had no role in study design, data collection and analysis, decision to publish, or preparation of the manuscript.

Copyright: @ 2020 Yang Z et al. This is an open access article distributed under the terms of the Creative Commons Attribution License, which permits unrestricted use, distribution, and reproduction in any medium, provided the original work is properly cited.

How to cite this article: Yang Z, Bedugnis A, Levinson $\mathrm{S}$ et al. Delayed administration of recombinant plasma gelsolin improves survival in a murine model of severe influenza [version 2; peer review: 2 approved] F1000Research 2020, 8:1860

https://doi.org/10.12688/f1000research.21082.2

First published: 06 Nov 2019, 8:1860 https://doi.org/10.12688/f1000research.21082.1 


\section{REVISED Amendments from Version 1}

As suggested by reviewer 1 , we clarified the housing strategy, the time of day of infection and the rationale for use of male mice. We also included text to explain the reason for using human rather than mouse gelsolin, and provided more details about the dosage protocol for the experiment which was used for transcriptome profiling. We added discussion to address the limitations of the 12-day duration of the survival studies used. We also included a number of revisions suggested by reviewer 2 to improve the clarity of the writing. The revised version clarifies that gene enrichment analysis was performed using the full down-regulated gene list. Finally, a comment speculating on the possible advantage of combining plasma gelsolin with other therapeutics was added to the discussion.

Any further responses from the reviewers can be found at the end of the article

\section{Introduction}

Seasonal influenza continues to be a cause of substantial morbidity and mortality. There is also a fear that a new virulent influenza strain could cause high death rates, similar to those seen during the 1918 pandemic $^{1}$. The 2009 pandemic revealed the limitations of available public health interventions and current vaccines $^{2}$. While some antiviral drugs (e.g., oseltamivir) are currently in use, they suffer from a short time window of efficacy and increasing viral resistance ${ }^{3}$. Hence, a substantial but unmet need exists for new therapeutic agents, especially for life-threatening infections.

The pathogenesis of influenza involves dysregulated and injurious host inflammatory responses ${ }^{4-6}$. This observation suggests that better inflammation control with immunomodulatory therapy may be able to reduce the morbidity and mortality seen in severe infections. Recombinant human plasma gelsolin (rhu-pGSN) is an attractive candidate because it dampens excessive and injurious inflammation and augments antimicrobial defenses. Moreover, it has successfully passed several of the safety, toxicity, and regulatory tests needed to go from 'bench to bedside'

Gelsolin was first identified in the cytoplasm of macrophages. It was further identified in many vertebrate cells, and is a highly conserved protein with many functions ${ }^{7,8}$. A unique characterstic of gelsolin at the gene level is the existence of a splice variant which encodes a distinct plasma isoform (pGSN). This isoform is released into extracellular fluids and differs from its cytoplasmic counterpart by the inclusion of an additional 25 amino acids at the $\mathrm{N}$-terminal sequence. Normal mammalian blood contains pGSN at concentrations of 200-300 $\mu \mathrm{g} / \mathrm{ml}$, making it one of the most abundant proteins in plasma.

One of pGSN's many functions is to dissolve the actin gels that arise from cellular debris, hence its name. These gels form a biofilm that reduces the ability of cellular and humoral defenses to gain access to embedded pathogenic organisms. In response, pGSN accumulates at sites of tissue damage. Interaction with actin reduces pGSN's binding to and inactivation of a host of microbial toxins and inflammatory mediators (for example, lysophosphatidic acid, sphingosine-1-phosphate, platelet-activating factor, fibronectin, endotoxin and lipoteichoic acid). The local dynamic balance of these mediators can modulate host defense $^{9,10}$. A complementary function of pGSN is its ability to augment the phagocytosis and killing of both Gram-positive and -negative bacteria by macrophages ${ }^{11}$. By stripping actin off macrophage scavenger receptors, pGSN promotes phagocytosis. It also enhances killing by stimulating the constitutive NOS3 enzyme system ${ }^{11,12}$. As the acute injury subsides, pGSN is free to bind and inhibit inflammatory substances, promoting resolution of injury at the infectious site. The local capture of pGSN by exposed actin reduces the levels of pGSN in the circulation commensurate to the magnitude of tissue injury. The relative abundance of pGSN typically allows it to render inactive any pro-inflammatory mediators that enter the systemic circulation and helps to prevent organ damage distant from the injury site. In severe infection, systemic depletion of pGSN can result in loss of its protective effects. Indeed, there is a robust correlation between how much pGSN levels decrease and probability of mortality. As might be predicted from these observations, systemic treatment with pGSN has reduced pathologic changes and mortality in numerous preclinical animal disease models ${ }^{7,13,14}$.

Relevant to the severe pneumonia seen in fatal influenza, administration of rhu-pGSN improved survival in murine primary or secondary (post-influenza) pneumococcal pneumonia, a benefit seen without any antibiotic treatment ${ }^{11,15}$. These results have established proof-of-principle for the potential benefit of rhu-pGSN for bacterial pneumonias, including the secondary pneumonias often found as a complication of influenza. Here we report that rhu-pGSN improves outcomes in a mouse primary influenza model without superimposed bacterial infections.

\section{Methods}

All protocols were approved by the Harvard Medical Area Biosafety and Animal Care and Use Committees.

\section{Mouse model of influenza}

Normal 6- to 8-week-old male CD1 mice were obtained from Charles River Laboratories (Wilmington, MA). Only male mice were used due to budgetary and time limits. All mice arrived and were co-housed 1 week prior to the start of the experiments. Each trial used a separate batch of mice. A murine-adapted strain of H1N1 influenza virus, A/Puerto Rico/8/1934 (PR8), quantified as plaque-forming units (PFU) was procured from ViraSource (Durham, NC). Mice were anesthetized with $72 \mathrm{mg} / \mathrm{kg}$ ketamine plus $9.6 \mathrm{mg} / \mathrm{kg}$ xylazine administered via intraperitoneal injection. Mice then received an intranasal instillation of $25 \mu \mathrm{l}$ suspension of PBS containing virus (ranging from 400-1000 PFU depending on the trial) or vehicle alone. All infections were done at approximately the same time of day (starting at $\sim 10 \mathrm{AM}$ ). Initial titration identified $400 \mathrm{PFU}$ as a dose that led to $\sim 60 \%$ mortality in vehicle-treated mice, and this dose was used in a majority of the trials (see Table 1). Most trials used at least 10 mice per group for the vehicle and pGSN treatment groups; details of the influenza dose, total number of mice, and their weights are provided in the tables in Underlying Data ${ }^{16}$. 
Table 1. Details of treatment trials using recombinant human plasma gelsolin (rhu-pGSN) in murine influenza.

\begin{tabular}{|c|c|c|c|c|c|c|c|c|c|}
\hline \multirow[t]{2}{*}{ Trial \# } & \multirow{2}{*}{$\begin{array}{l}\text { Virus dose } \\
\text { (PFU) }\end{array}$} & \multirow{2}{*}{$\begin{array}{l}\text { Treatment } \\
\text { (start day) }\end{array}$} & \multirow{2}{*}{$\begin{array}{l}\text { pGSN dose } \\
(\mathrm{mg})\end{array}$} & \multirow{2}{*}{$\begin{array}{l}\text { Treatment } \\
\text { days }\end{array}$} & \multicolumn{2}{|c|}{$\begin{array}{l}\text { mice per } \\
\text { group, } n\end{array}$} & \multicolumn{2}{|c|}{ Survival, \% } & \multirow[t]{2}{*}{ Benefit } \\
\hline & & & & & Vehicle & pGSN & Vehicle & pGSN & \\
\hline 1 & 400 & 6 & 5 & $d 6-11$ & 10 & 10 & 10 & 60 & YES \\
\hline 2 & 400 & 6 & 5 & $d 6-11$ & 10 & 9 & 40 & 44 & NO \\
\hline \multirow[t]{2}{*}{3} & 500 & 3 & 5 & d3-11 & 10 & 10 & 50 & 20 & NO \\
\hline & 500 & 6 & 5 & $d 6-11$ & & 10 & & 44 & NO \\
\hline 4 & 500 & 6 & 5 & d6-11 & 10 & 10 & 20 & 40 & YES \\
\hline 5 & 1000 & 6 & 5 & d6-11 & 10 & 10 & 20 & 0 & NO \\
\hline 6 & 400 & 6 & 5 & d6-11 & 10 & 10 & 50 & 70 & YES \\
\hline 7 & 600 & 6 & 5 & d6-11 & 10 & 10 & 40 & 30 & NO \\
\hline \multirow[t]{2}{*}{8} & 400 & 6 & 5 & $d 6-11$ & 14 & 13 & 50 & 62 & YES \\
\hline & 400 & 6 & 8 & d6-11 & & 10 & & 80 & YES \\
\hline \multirow[t]{2}{*}{9} & 400 & 6 & 8 & d6-11 & 15 & 15 & 40 & 67 & YES \\
\hline & 400 & 6 & 10 & d6-8 & & 10 & & 70 & YES \\
\hline \multirow[t]{2}{*}{10} & 400 & 6 & 5 & $d 6-11$ & 15 & 10 & 57 & 70 & YES \\
\hline & 400 & 6 & 8 & $d 6-11$ & & 15 & & 80 & YES \\
\hline \multirow[t]{3}{*}{11} & 400 & 3 & 5 & d3-11 & 10 & 10 & 60 & 90 & YES \\
\hline & 400 & 3 & 8 & d3-11 & & 10 & & 80 & YES \\
\hline & 400 & 6 & 8 & $d 6-11$ & & 10 & & 70 & YES \\
\hline \multirow[t]{3}{*}{12} & 500 & 3 & 5 & d3-11 & 10 & 10 & 40 & 90 & YES \\
\hline & 500 & 3 & 5 & d3-5 & & 10 & & 70 & YES \\
\hline & 500 & 6 & 5 & d6-11 & & 10 & & 60 & YES \\
\hline 13 & 500 & 3 & 5 & $d 3-11$ & 22 & 19 & 59 & 50 & NO \\
\hline \multirow[t]{4}{*}{14} & 500 & 3 & 5 & d3-11 & 18 & 7 & 39 & 57 & YES \\
\hline & 500 & & 5 & $d 3-11$ & & 9 & & 56 & YES \\
\hline & 500 & & 5 & d3-11 & & 8 & & 38 & NO \\
\hline & 500 & & 5 & d3-11 & & 8 & & 50 & YES \\
\hline \multirow[t]{2}{*}{15} & 400 & 3 & $2.5,5$ & $\begin{array}{c}2.5 d 3-5 \\
5 d 6-11\end{array}$ & 19 & 13 & 42 & 77 & YES \\
\hline & 400 & 6 & 5 & $5 \mathrm{~d} 6-11$ & & 12 & 42 & 50 & NO \\
\hline \multirow[t]{3}{*}{16} & 400 & 3 & 2.5 & $2.5 d 3-11$ & 13 & 12 & 46 & 75 & YES \\
\hline & 400 & 3 & $2.5,5$ & $\begin{array}{c}2.5 \mathrm{~d} 3-5 \\
5 \mathrm{~d} 6-11\end{array}$ & & 12 & 46 & 50 & NO \\
\hline & 400 & 3 & $2.5,5$ & $\begin{array}{c}2.5 d 3-5 \\
5 \text { d7 }-11\end{array}$ & & 12 & 46 & 83 & YES \\
\hline \multirow[t]{3}{*}{17} & 400 & 3 & $0.5,3$ & $\begin{array}{c}0.5 \mathrm{~d} 3-6 \\
3 \mathrm{~d} 7-11\end{array}$ & 18 & 15 & 50 & 60 & YES \\
\hline & 400 & 3 & 1,3 & $\begin{array}{l}1 \mathrm{~d} 3-6 \\
3 \mathrm{~d} 7-11\end{array}$ & & 15 & & 47 & NO \\
\hline & 400 & 3 & 2,5 & $\begin{array}{l}2 \text { d3-6, } \\
5 \text { d7 }-11\end{array}$ & & 12 & & 83 & YES \\
\hline \multirow[t]{2}{*}{18} & 400 & 3 & 1,5 & $\begin{array}{l}1 d 3-6 \\
5 d 6-11\end{array}$ & 17 & 13 & 47 & 54 & NO \\
\hline & 400 & 3 & 2,5 & $\begin{array}{l}2 d 3-6 \\
5 d 7-11\end{array}$ & & 10 & & 70 & YES \\
\hline
\end{tabular}

* Treatment benefit scored as Yes if $\%$ survival $\geq 10 \%$ better with pGSN vs. Vehicle; No if $\%$ survival $<10 \%$ better with pGSN. 
Treatments and outcomes

Recombinant human pGSN (rhu-pGSN) was synthesized in E. coli and purified by Fujifilm Biosynth (Billingham, UK). We used human rather than murine gelsolin based on prior demonstrations of function of rhu-pGSN in rodent models and because data with the human gelsolin will facilitate clinical translation efforts. Rhu-pGSN was administered daily to mice by subcutaneous injection starting on day 3 or 6 after infection, at doses ranging from $0.5-5 \mathrm{mg}$ as detailed in the Results. We monitored the mice for 12 days, measuring survival, changes in weight and overall morbidity using a composite index (i.e., 1 point each for hunched appearance, ruffled fur or partly closed eyes; 1.5 points for prolapsed penis or splayed hind quarter; 2 points for listlessness, with a maximum score of 8 ; the assessment was performed without blinding to treatment group) adapted from guidelines described previously ${ }^{17}$. Weights and morbidity scores for the last day alive were carried forward for animals that did not survive.

\section{Lung transcriptome profiling}

Lung tissue was obtained on days 7 and 9 after infection from mice treated with either vehicle or rhu-pGSN (dosed $2 \mathrm{mg}$ per day starting on day 3 after infection, then increased to $5 \mathrm{mg}$ per day on day 7). RNA was isolated using the RNAEasy mini-kit (Qiagen, Germantown, MD) according to manufacturer's instructions. RNA samples were analyzed using the Mouse DriverMap targeted gene expression profiling panel from Cellecta (Mountain View, CA). The Cellecta platform uses highly multiplexed RT-PCR amplification and next-generation sequencing (NGS) quantitation to measure expression of 4753 protein-coding and functionally significant mouse genes. The procedure detailed in the Cellecta User Manual, item 5.3 was followed to create amplified index libraries which were sequenced on a Illumina NextSeq 500 instrument. The sequencing data was converted to FASTQ format and then further analyzed using DriverMap Sample Extraction software. This produces a raw data matrix file of counts for each sample in columns aligned to the 4753 gene panel.

\section{Statistical analysis}

Data were analyzed using Prism (GraphPad Software) or SAS (SAS Institute) software. Differences in Kaplan-Meier survival curves were analyzed using a log-rank test with Sidak adjustment for multiple comparisons. A Breslow-Day test for homogeneity of the pGSN versus vehicle comparison across studies yielded $\mathrm{p}>0.2$, indicating homogeneity could not be rejected and supporting the overall comparison across studies, which was carried out via the log-rank (Mantel-Cox) test stratified by trial. For other measurements, differences between groups were examined by ANOVA. The transcriptome profiling results scaled to normalize column counts, were converted to $\log 2$ counts (after addition of 0.1 to all cells to eliminate zero values) and then analyzed using Qlucore software (Lund, Sweden). Further analysis of gene set enrichment was performed using tools (Panther version $14.1^{18}$ and MetaCore (version 19.3, Clarivate Analytics, Philadelphia, PA)) that allow evaluation using a custom background gene list (i.e., the $~ 4700$ genes measured using the Cellecta DriverMap platform).

\section{Results}

\section{Effect of rhu-pGSN on survival}

We tested a variety of dose and timing regimens to evaluate the potential of rhu-pGSN to improve outcomes, conducting a total of 18 trials that are tabulated in Table 1 and summarized in Table 2. To mimic likely clinical usage, mice were not treated until several days post-challenge.

The main finding was that delayed treatment with rhu-pGSN resulted in significant improvement in the survival of mice (Figure 1). All studies combined yielded 39\% (93/236) surviving mice treated with vehicle and $62 \%$ (241/389) surviving mice treated with pGSN on day $12(\mathrm{p}=0.000001$, Figure $1 \mathrm{~A})$. Improved survival was observed whether the delayed treatment was started on day 6 (Figure 1C) or day 3 after infection (Figures 1E, G). Similarly, compared to vehicle treatment, rhu-pGSN resulted in decreased morbidity scores (Figures 1B, D, $\mathrm{F}, \mathrm{H})$. In contrast, no statistically significant difference in weight

Table 2. Summary of survival data using different treatment regimens.

\begin{tabular}{|c|c|c|c|c|c|c|c|c|c|}
\hline Subset analyzed & $\begin{array}{l}\text { Experiments } \\
\text { analyzed, } n\end{array}$ & $\begin{array}{l}\text { Viral dose, } \\
\text { PFU(cohorts } \\
\text { tested, } n \text { ) }\end{array}$ & $\begin{array}{l}\text { Vehicle } \\
\text { start, } \mathrm{n}\end{array}$ & $\begin{array}{l}\text { Vehicle } \\
\text { survived, } \\
\text { n }\end{array}$ & $\begin{array}{l}\text { Vehicle } \\
\text { survival, } \\
\%\end{array}$ & $\begin{array}{l}\text { pGSN } \\
\text { start, } \\
\text { n }\end{array}$ & $\begin{array}{l}\text { pGSN } \\
\text { survived, } \\
n\end{array}$ & $\begin{array}{l}\text { pGSN } \\
\text { survival, } \\
\%\end{array}$ & p-value \\
\hline All data & 18 & $\begin{array}{c}400(21) ; 500(11) \\
600(1) ; 1000(1)\end{array}$ & 236 & 93 & 39 & 389 & 241 & 62 & $<0.000001$ \\
\hline Treatment d6-11 & 11 & $\begin{array}{l}400(11) ; 500(4) ; \\
600(1) ; 1000(1)\end{array}$ & 148 & 59 & 40 & 172 & 110 & 64 & 0.000011 \\
\hline Treatment d3-11 2mg+ & 9 & $400(7) ; 500(7)$ & 137 & 58 & 42 & 162 & 101 & 62 & 0.0005 \\
\hline $\begin{array}{l}\text { Treatment start low } 2 \\
\mathrm{mg}+(\mathrm{d} 3-6 / 7) \text { then high } \\
\text { dose }\end{array}$ & 4 & $400(6)$ & 67 & 34 & 51 & 71 & 55 & 77 & 0.0005 \\
\hline $\begin{array}{l}\text { Treatment start very } \\
\text { low }(0.5-1) \mathrm{mg}+(\mathrm{d} 3-6 / 7) \\
\text { then high dose }\end{array}$ & 3 & $400(3)$ & 35 & 19 & 54 & 43 & 24 & 56 & 0.62 \\
\hline
\end{tabular}

pGSN, plasma gelsolin 

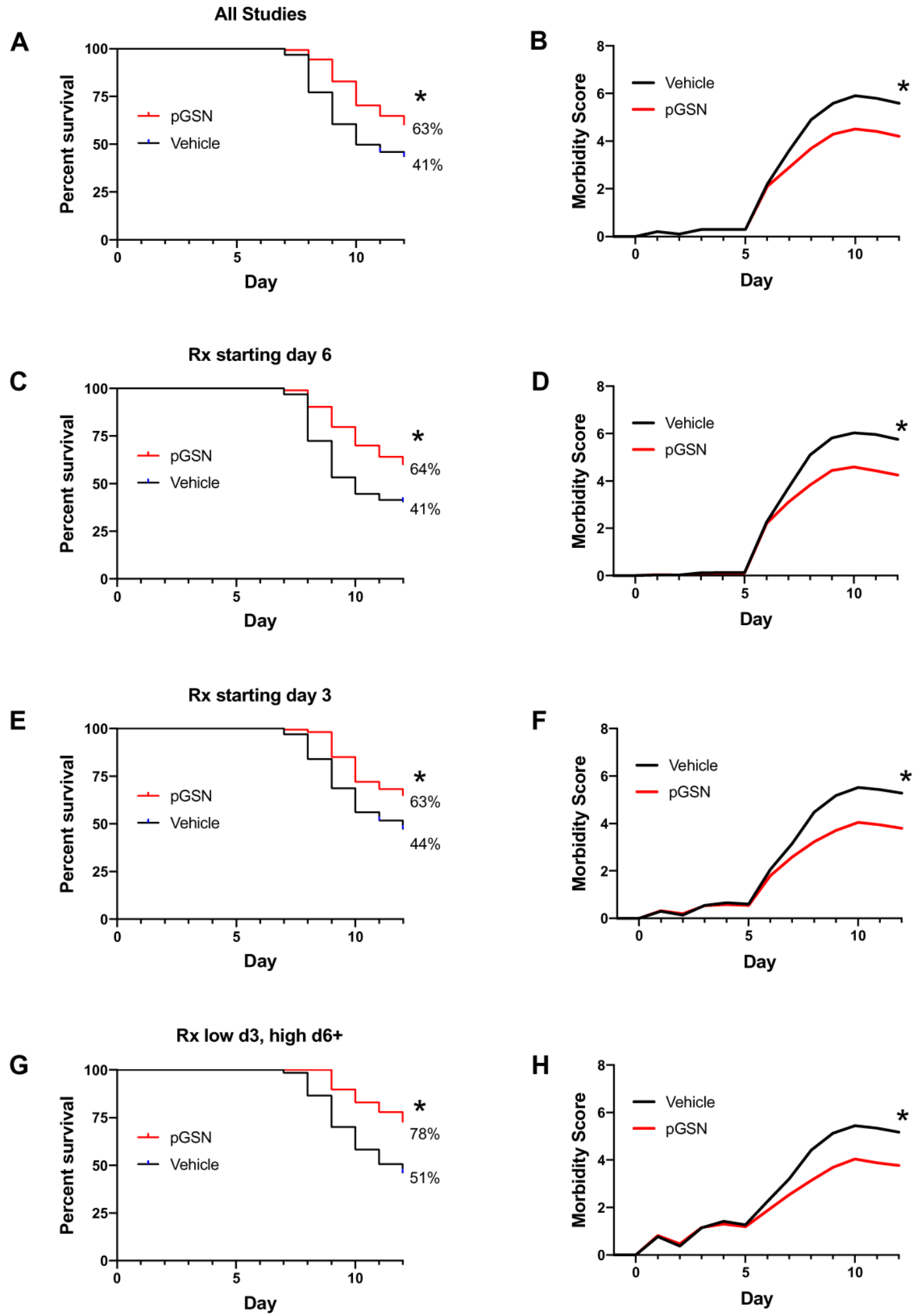

Figure 1. Survival and morbidity analysis of different treatment regimens. Comparison of survival rates $(\mathbf{A}, \mathbf{C}, \mathbf{E}, \mathbf{G})$ and morbidity $(\mathbf{B}, \mathbf{D}, \mathbf{F}, \mathbf{H})$ in mice treated with rhu-pGSN or vehicle. (A, B) Results for all 18 trials (typically 10 or more mice per group, see details in Table 1 and Table 2) using delayed treatment. Some trials initiated treatment in different arms on day 6 or day 3. (C, D) Results for 13 trials using delayed treatment starting on day 6 or later. (E, F) Results for eight trials using treatment starting on day 3 . (G, H) Results for four trials starting with an initially lower dose on day 3 with an increased dose starting on day $6 / 7 .{ }^{*}=0.000001,0.00001,0.0005,0.0005$ for $A, C, E, G$, respectively; $P<0.0001$ for $B, D, F, H$. 
loss or recovery (in surviving animals) was consistently observed in the experiments summarized in Figure 1. The sole exception was found in the trials testing a dose regimen of initially low (> $2 \mathrm{mg}$ rhu-pGSN on days $3-6 / 7$, then $5 \mathrm{mg}$ through day 11). The latter set of trials led to weights (compared to day 0) at the end of study of $81.4 \pm 4.7 \%$ in vehicle-treated mice versus $85 \pm 2.6 \%$ in pGSN-treated mice $(\mathrm{p}<0.0001$, summary of 4 trials, see also Table 1 and Table 2, and more detailed tabulation of all experiments in Extended data ${ }^{16}$. A beneficial effect of rhu-pGSN was observed in a majority but not all of the 18 individual trials (Table 1, see Discussion).

\section{Transcriptome profiling}

To evaluate whether rhu-pGSN treatment modified the transcriptome profile (see Underlying data) of infected lungs, we harvested lung tissue just before (day 7) and after (day 9) the usual onset of mortality (day 8 ) in this model $(n=5$ per group per day). Per protocol, the rhu-pGSN dose was increased in this experiment on day 7, between the 2 timepoints selected for profiling. Comparison of lung samples obtained at day 7 from vehicle-treated and rhu-pGSN-treated mice showed no significant differences. In contrast, analysis of day 9 samples identified 344 differentially expressed genes in the rhupGSN-treated group, comprised of 195 down-regulated and 149 up-regulated genes. The top 50 up- and down-regulated genes are shown in Figure 2, which is notable for the many cytokine and immune-related genes prominent among those downregulated in the rhu-pGSN-treated group (including IL10, IL12rb, CTLA4, and CCRs9, 7 and 5, among others). We performed gene enrichment analysis of the full down-regulated gene list using the
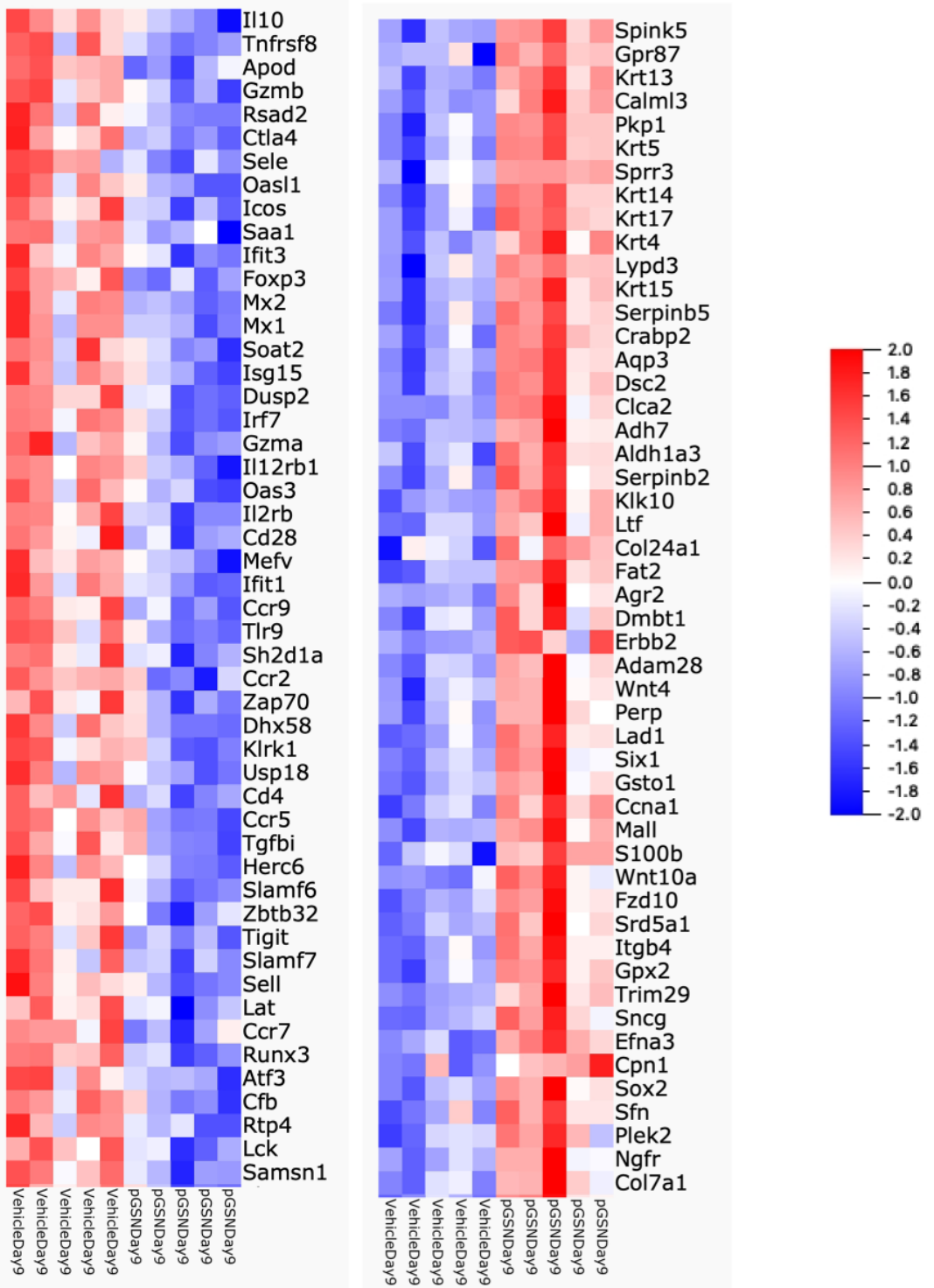

Figure 2. Top 50 up- and down- regulated differentially expressed genes in lung tissue from vehicle or rhu-pGSN treated animals (Day 9). Heat map showing top 50 down-regulated (left) and up-regulated (right) genes in the lungs of rhu-pGSN treated animals on day 9 (range -2 (blue) to +2 (red)) 
Panther online analysis tool to query GO Ontology or Reactome databases. The main findings were a reduction of expression of biological processes linked to immune and inflammatory responses, or release of cytokine and other cellular activators. The top 10 most significant processes/pathways are shown in Table 3. Analysis using a different gene enrichment analysis software tool (MetaCore) produced similar results. Analysis of the up-regulated gene list identified enrichment of processes related to tissue morphogenesis and epithelial/epidermal cell differentiation (consistent with repair of influenza-mediated damage, see Discussion). We present details of the DriverMap gene list, the differentially expressed genes identified, and the full results of gene enrichment analyses using the down- and up-regulated gene lists to query the Panther and MetaCore databases in worksheets $2-15$ in a spreadsheet available in Extended data ${ }^{19}$.

\section{Discussion}

We sought to evaluate the potential of rhu-pGSN to improve outcomes in severe influenza using a clinically relevant scenario of delaying initiation of treatment. The key finding was that delayed pGSN treatment significantly improved survival, either when used starting on day 3 or even starting as late as day 6 after infection. In addition to the impractically of initiating earlier therapy right after infection (as opposed to the onset of severe symptoms) in patients, we did not want to interfere with the immediate immune response to influenza given the detrimental consequences observed in some experimental models.

Some limitations merit discussion. The first is the experimental variability we observed and report. Treatment with rhu-pGSN increased survival in a majority of the experiments conducted,

\section{Table 3. Top 10 down-regulated Gene Ontology (GO) processes and pathways in plasma gelsolin (pGSN)-treated lung tissue} (Day 9).

\begin{tabular}{|c|c|c|c|c|c|c|}
\hline \multirow[b]{2}{*}{ GO biological process } & \multirow[b]{2}{*}{$\begin{array}{l}\text { Process } \\
\text { genes in } \\
\text { background } \\
\text { list, } n\end{array}$} & \multicolumn{5}{|c|}{ Day 9 downregulated genes in pGSN-treated group } \\
\hline & & $\begin{array}{c}\text { Genes in day } \\
9 \text { downreg } \\
\text { genes in pGSN } \\
\text { group, } n\end{array}$ & $\begin{array}{l}\text { Expected } \\
\text { genes, } n\end{array}$ & $\begin{array}{l}\text { Fold } \\
\text { enrichment }\end{array}$ & $\begin{array}{c}\text { Raw } \\
\text { P-value }\end{array}$ & FDR \\
\hline immune system process (GO:0002376) & 932 & 126 & 38.5 & 3.27 & 4.13E-40 & 5.59E-36 \\
\hline immune response (GO:0006955) & 496 & 88 & 20.49 & 4.29 & 9.01E-33 & $6.09 E-29$ \\
\hline defense response (GO:0006952) & 534 & 83 & 22.06 & 3.76 & $6.69 \mathrm{E}-27$ & $3.02 E-23$ \\
\hline response to external biotic stimulus (GO:0043207) & 500 & 78 & 20.66 & 3.78 & 4.19E-25 & $9.44 \mathrm{E}-22$ \\
\hline response to biotic stimulus (GO:0009607) & 511 & 79 & 21.11 & 3.74 & 3.03E-25 & 1.03E-21 \\
\hline response to other organism (GO:0051707) & 500 & 78 & 20.66 & 3.78 & 4.19E-25 & 1.13E-21 \\
\hline regulation of immune system process (G0:0002682) & 682 & 90 & 28.18 & 3.19 & 8.49E-25 & 1.64E-21 \\
\hline $\begin{array}{l}\text { positive regulation of immune system process } \\
\text { (GO:0002684) }\end{array}$ & 485 & 75 & 20.04 & 3.74 & 8.83E-24 & 1.49E-20 \\
\hline response to external stimulus (GO:0009605) & 928 & 100 & 38.34 & 2.61 & 8.64E-22 & $1.30 \mathrm{E}-18$ \\
\hline defense response to other organism (GO:0098542) & 343 & 61 & 14.17 & 4.3 & 1.14E-21 & $1.54 \mathrm{E}-18$ \\
\hline \multicolumn{7}{|l|}{ Reactome pathways } \\
\hline Immune System (R-MMU-168256) & 773 & 85 & 31.94 & 2.66 & $2.92 \mathrm{E}-18$ & $4.52 \mathrm{E}-15$ \\
\hline $\begin{array}{l}\text { Cytokine Signaling in Immune system (R-MMU- } \\
\text { 1280215) }\end{array}$ & 257 & 38 & 10.62 & 3.58 & $3.48 \mathrm{E}-11$ & 2.69E-08 \\
\hline Adaptive Immune System (R-MMU-1280218) & 299 & 37 & 12.35 & 3 & $6.13 E-09$ & 3.16E-06 \\
\hline Metabolism (R-MMU-1430728) & 783 & 8 & 32.35 & 0.25 & $1.48 \mathrm{E}-07$ & $5.72 \mathrm{E}-05$ \\
\hline $\begin{array}{l}\text { Immunoregulatory interactions between a Lymphoid } \\
\text { and a non-Lymphoid cell (R-MMU-198933) }\end{array}$ & 55 & 14 & 2.27 & 6.16 & 3.39E-07 & 1.05E-04 \\
\hline Innate Immune System (R-MMU-168249) & 453 & 43 & 18.72 & 2.3 & $5.72 \mathrm{E}-07$ & $1.48 \mathrm{E}-04$ \\
\hline Signaling by Interleukins (R-MMU-449147) & 192 & 24 & 7.93 & 3.03 & 3.33E-06 & 7.37E-04 \\
\hline GPVI-mediated activation cascade (R-MMU-114604) & 26 & 9 & 1.07 & 8.38 & 5.84E-06 & 1.13E-03 \\
\hline DAP12 interactions (R-MMU-2172127) & 20 & 7 & 0.83 & 8.47 & $6.27 \mathrm{E}-05$ & 1.08E-02 \\
\hline Interleukin-2 family signaling (R-MMU-451927) & 30 & 8 & 1.24 & 6.45 & 9.32E-05 & 1.31E-02 \\
\hline
\end{tabular}


but not in all of them. For a subset of the negative trials, we could postulate plausible potential explanations (e.g., technical issues with the virus stock, variation in instillation method, insufficient initial rhu-pGSN dose in the 'low dose then high dose' trials). To the extent possible, we adjusted our methods to reduce these potential sources of variability. However, for the remainder of the negative trials, we simply do not have a good explanation for the outcome. Hence, we have chosen to present all the data whether positive or negative to provide a full report of the findings.

We also manipulated the experimental variables, in part to address larger questions (e.g., can treatment as late as day 6 vs day 3 after onset of infection be effective?) and in some cases to explore potential reasons for the intermittent variability in our results (e.g., trial 14 tested the potential influence of differences in initial weight of the mice we used). Ultimately, we observed beneficial effects whether the survival analysis included all the trials (Figures 1A, B) or those using treatment starting at day 6 or day 3 (Figures $1 \mathrm{C}-\mathrm{H}$ ).

Mice were only followed for 12 days when euthanasia was performed on surviving mice. Since the survival curves were still potentially declining, the ultimate mortality rate could not be confidently ascertained. However, the time to death at a minimum was prolonged with rhu-pGSN over placebo treatment.

Notably, rhu-pGSN did not rescue all of the mice dying from influenza in our model, offering only a partial (albeit significant) survival benefit. Given the goal of identifying a novel therapy for severe influenza, an optimistic interpretation is that this occurred in mice without the supportive fluid and respiratory care given to hospitalized patients, and that similar or more robust benefits might be observed in the clinical setting. We can also speculate that combination therapy might offer a greater survival advantage. The results establish a potential benefit for rhu-pGSN but this potential needs further evaluation in a larger animal model, e.g. ferret ${ }^{20}$ and then (if results warrant), testing in a clinical trial to determine its role in therapy for severe influenza in human patients. Our findings rely on studies with only one strain of influenza in only one strain of one model species, the mouse. Nevertheless, we favor future experimentation in a larger animal model as the logical next step, rather than further studies in mice. Additional investigations using other influenza or mouse strains would not resolve the suggestion (hope) of possible clinical benefit offered by our results. Hence, large animal experiments deserve priority.

Our study did not address the mechanism(s) for the beneficial action of rhu-pGSN. The available literature identifies numerous inflammatory mediators whose function can be modulated by pGSN (e.g. sphingosine-1-phophate ${ }^{9}$, endotoxin ${ }^{10}$, platelet activating factor $\left.^{21}\right)$. The transcriptome profiling results are consistent with a beneficial down-regulation of the overly exuberant immune and inflammatory response that characterizes severe influenza ${ }^{22-24}$. Further investigation of the many possible single or combination targets by which pGSN may be acting is warranted. However, a complete delineation of its mechanisms will take substantial effort and time to achieve. If effective, therapeutic use of rhu-pGSN should be pursued even in the absence of a full map of its complex effects. This position reflects in part the fact that pGSN is a normal, abundant protein in human plasma, and has passed initial safety evaluation in human subjects hospitalized for non-severe community acquired pneumonia (ClinicalTrials.gov NCT03466073). Finally, it is worth speculating that rhu-pGSN treatment may also benefit patients with severe influenza by reducing the risk of the common complication of secondary bacterial pneumonia ${ }^{25,26}$. This possibility is suggested by other studies from our laboratory, showing rhu-pGSN improved survival of mice with post-influenza bacterial pneumonia ${ }^{11}$.

In summary, rhu-pGSN can improve outcomes in a highly lethal murine influenza model when given after a clinically relevant delay. These findings are consistent with the benefits seen in models of pneumococcal pneumonia. The modes of action for pGSN involve host responses and do not seem to depend on the specific type of pathogen. Our findings support further investigation of pGSN as an adjunctive therapy for severe influenza and other viral infections.

\section{Data availability}

Underlying data

Harvard Dataverse: Expanded Tables 1 \& 2. https://doi.org/10.7910/ DVN/53GJY1 ${ }^{16}$.

This project contains data on each experimental group, as shown in Table 1 and Table 2, with additional variables, such as weight, and statistical analyses.

NCBI Gene Expression Omnibus: Transcriptome profiling of lung tissue from influenza-infected mice treated with plasma gelsolin. Accession number GSE138986; https://identifiers.org/ geo:GSE138986.

\section{Extended data}

Harvard Dataverse: Transcriptome analysis of gelsolin vs vehicle treatment in mouse influenza infected lungs. https://doi.org/ 10.7910/DVN/8HBFD7 ${ }^{19}$.

\section{Reporting guidelines}

Harvard Dataverse: ARRIVE checklist for 'Delayed administration of recombinant plasma gelsolin improves survival in a murine model of severe influenza'. https://doi.org/10.7910/DVN/ VQBKLF ${ }^{27}$.

Data hosted on Harvard Dataverse are available under the terms of the Creative Commons Zero "No rights reserved" data waiver (CC0 1.0 Public domain dedication).

\section{Acknowledgements}

The authors thank Dr. James Bolognese for consultation on statistical analysis. 
1. Morens DM, Taubenberger JK: Pandemic influenza: certain uncertainties. Rev Med Virol. 2011; 21(5): 262-84 PubMed Abstract | Publisher Full Text | Free Full Text

2. Fineberg HV: Pandemic preparedness and response--lessons from the H1N Influenza of 2009. N Engl J Med. 2014; 370(14): 1335-42. PubMed Abstract | Publisher Full Text

3. Lackenby A, Besselaar TG, Daniels RS, et al.: Global update on the susceptibility of human influenza viruses to neuraminidase inhibitors and status of novel antivirals, 2016-2017. Antiviral Res. 2018; 157: 38-46. PubMed Abstract | Publisher Full Text | Free Full Text

4. Iwasaki A, Pillai PS: Innate immunity to influenza virus infection. Nat Rev Immunol. 2014; 14(5): 315-28.

PubMed Abstract | Publisher Full Text | Free Full Text

5. Herold S, Becker C, Ridge KM, et al:: Influenza virus-induced lung injury: pathogenesis and implications for treatment. Eur Respir J. 2015; 45(5): 1463-78. PubMed Abstract | Publisher Full Text

6. Gregory DJ, Kobzik L: Influenza lung injury: mechanisms and therapeutic opportunities. Am J Physiol Lung Cell Mol Physiol. 2015; 309(10): 1041-6. PubMed Abstract | Publisher Full Text | Free Full Text

7. Piktel E, Levental I, Durnas B, et al.: Plasma Gelsolin: Indicator of Inflammation and Its Potential as a Diagnostic Tool and Therapeutic Target. Int J Mol Sci. 2018; 19(9): pii: E2516.

PubMed Abstract | Publisher Full Text | Free Full Text

8. Silacci P, Mazzolai L, Gauci C, et al: Gelsolin superfamily proteins: key regulators of cellular functions. Cell Mol Life Sci. 2004; 61(19-20): 2614-23. PubMed Abstract | Publisher Full Text

9. Bucki R, Kulakowska A, Byfield FJ, et al.: Plasma gelsolin modulates cellular response to sphingosine 1-phosphate. Am J Physiol Cell Physiol. 2010; 299(6): C1516-23.

PubMed Abstract | Publisher Full Text | Free Full Text

10. Bucki R, Georges PC, Espinassous Q, et al:: Inactivation of endotoxin by human plasma gelsolin. Biochemistry. 2005; 44(28): 9590-7. PubMed Abstract | Publisher Full Text

11. Yang Z, Chiou TT, Stossel TP, et al:: Plasma gelsolin improves lung host defense against pneumonia by enhancing macrophage NOS3 function. Am J Physiol Lung Cell Mol Physiol. 2015; 309(1): L11-6.

PubMed Abstract | Publisher Full Text | Free Full Text

12. Ordija CM, Chiou TT-Y, Yang Z, et al.: Free actin impairs macrophage bacterial defenses via scavenger receptor MARCO interaction with reversal by plasma gelsolin. Am J Physiol Lung Cell Mol Physiol. 2017; 312(6): L1018-L1028. PubMed Abstract | Publisher Full Text | Free Full Text

13. Cohen TS, Bucki R, Byfield FJ, et al.: Therapeutic potential of plasma gelsolin administration in a rat model of sepsis. Cytokine. 2011; $54(3): 235-8$. PubMed Abstract | Publisher Full Text | Free Full Text

14. Christofidou-Solomidou M, Scherpereel A, Solomides CC, et al.: Recombinant plasma gelsolin diminishes the acute inflammatory response to hyperoxia in mice. J Investig Med. 2002; 50(1): 54-60. PubMed Abstract | Publisher Full Text

15. Yang Z, Bedugnis A, Levinson S, et al: Delayed Administration of Recombinant Plasma Gelsolin Improves Survival in a Murine Model of Penicillin-Susceptible and Penicillin-Resistant Pneumococcal Pneumonia . J Infect Dis. 2019; 220(9): 1498-1502.

PubMed Abstract | Publisher Full Text | Free Full Text

16. Kobzik L: "Expanded Tables 1 \& 2". Harvard Dataverse, V1 2019. http://www.doi.org/10.7910/DVN/53GJY1

17. Burkholder T, Foltz C, Karlsson E, et al:: Health Evaluation of Experimental Laboratory Mice. Curr Protoc Mouse Biol. 2012; 2: 145-65. PubMed Abstract | Publisher Full Text | Free Full Text

18. Mi H, Muruganujan A, Casagrande JT, et al.: Large-scale gene function analysis with the PANTHER classification system. Nature Protocols. 2013; 8(8): 1551-66.

PubMed Abstract | Publisher Full Text | Free Full Text

19. Kobzik L: "Transcriptome analysis of gelsolin vs vehicle treatment in mouse influenza infected lungs". Harvard Dataverse, V1 2019. http://www.doi.org/10.7910/DVN/8HBFD7

20. Albrecht RA, Liu WC, Sant AJ, et al:: Moving Forward: Recent Developments for the Ferret Biomedical Research Model. MBio. 2018; 9(4): pii: e01113-18. PubMed Abstract | Publisher Full Text | Free Full Text

21. Osborn TM, Dahlgren C, Hartwig JH, et al:: Modifications of cellular responses to lysophosphatidic acid and platelet-activating factor by plasma gelsolin. $A m \mathrm{~J}$ Physiol Cell Physiol. 2007; 292(4): C1323-30. PubMed Abstract | Publisher Full Text

22. Kalil AC, Thomas PG: Influenza virus-related critical illness: pathophysiology and epidemiology. Crit Care. 2019; 23(1): 258.

PubMed Abstract | Publisher Full Text | Free Full Text

23. Gounder AP, Boon ACM: Influenza Pathogenesis: The Effect of Host Factors on Severity of Disease. J Immunol. 2019; 202(2): 341-350. PubMed Abstract | Publisher Full Text | Free Full Text

24. Biondo $\mathrm{C}$, Lentini $\mathrm{G}$, Beninati $\mathrm{C}$, et al:: The dual role of innate immunity during influenza. Biomed J. 2019; 42(1): 8-18.

PubMed Abstract | Publisher Full Text | Free Full Text

25. Shirey KA, Perkins DJ, Lai W, et al.: Influenza "Trains" the Host for Enhanced Susceptibility to Secondary Bacterial Infection. MBio. 2019; 10(3) pii: e00810-19.

PubMed Abstract | Publisher Full Text | Free Full Text

26. Smith AM, McCullers JA: Secondary bacterial infections in influenza virus Infection pathogenesis. Curr Top Microbiol Immunol. 2014; 385: 327-56. PubMed Abstract | Publisher Full Text

27. Kobzik L: "ARRIVE Guidelines checklist". Harvard Dataverse, V1 2019. http://www.doi.org/10.7910/DVN/VQBKLF 


\section{Open Peer Review}

\section{Current Peer Review Status:}

\section{Version 2}

Reviewer Report 21 February 2020

https://doi.org/10.5256/f1000research.24817.r60385

(C) 2020 Dockrell D. This is an open access peer review report distributed under the terms of the Creative Commons Attribution License, which permits unrestricted use, distribution, and reproduction in any medium, provided the original work is properly cited.

\section{David H. Dockrell}

MRC Centre for Inflammation Research, University of Edinburgh, Edinburgh, UK

The authors appear to have addressed the issues raised and clarified the main points raised in review.

Competing Interests: No competing interests were disclosed.

Reviewer Expertise: Pathogeneiss of infectious diseases, especially respiratory tract infections.

I confirm that I have read this submission and believe that I have an appropriate level of expertise to confirm that it is of an acceptable scientific standard.

\section{Version 1}

Reviewer Report 04 December 2019

\section{https://doi.org/10.5256/f1000research.23201.r56253}

(C) 2019 Fedson D. This is an open access peer review report distributed under the terms of the Creative Commons Attribution License, which permits unrestricted use, distribution, and reproduction in any medium, provided the original work is properly cited.

\section{David S Fedson}

None (retired, prolific writer on influenza and host-directed therapies), Sergy Haut, France

F1000RESEARCH - Submitted by David S. Fedson, MND

Yang Z, Bedugnis A, Levinson S, DiNubile M, Stossel T, Li Q, Kobzik L. Delayed administration of 
recombinant plasma gelsolin improves survival in a murine model of severe influenza. $F 1000$ Research 2019;8:1860.

\section{Reviewer's comments}

This straightforward paper presents the results of a study showing that rhu-pGSN improves survival in a mouse model of influenza. My answers to the mandatory questions above indicate the paper is acceptable and requires no significant modification. The comments below are suggestions and are offered in the hope they might help readers. The authors should feel free to ignore them if they wish.

Introduction, page 3, left column, paragraph 2 - The pathogenesis of influenza involves a dysregulated and injurious host response that is not wholly inflammatory. Inflammation is involved to be sure, but there is also a degree of immunosuppression. Some of the changes (e.g., pulmonary endothelial dysfunction) can be regarded as separate from inflammation and/or immunosuppression. The authors argue that rhu-pGSN is "an attractive candidate (for treatment) because it dampens excessive and injurious inflammation and augments antimicrobial defences". Rhu-pGSN probably does much more. (See Becker PM et al. Pulmonary vascular permeability and ischemic injury in gelsolin-deficient mice. Am J Respir Cell Mol Biol 2005;28:478-84 ${ }^{1}$ and earlier Kuhne W et al. Disintegration of cytoskeletal structure of actin filaments in energy-depleted endothelial cells. Am J Physiol 1993;265(5 Pt2):H1599-608².)

Page 3, left column, paragraph 4, lines 1-7 - The first 7 lines could be written more tightly. "One of pGSN's many functions is to dissolve the actin gels that arise from cellular debris, hence its name. These gels form a biofilm that reduces the ability of cellular and humoral defences to gain access to embedded pathogenic organisms. In response, pGSN accumulates at sites of tissue damage. Interaction with actin reduces pGSN's binding to ..." Also, in line 12, delete "final". This is not the final comment in this paragraph.

Page 3, right column, paragraph 1, lines 3-4 - A sentence could be added: “... levels decrease and probability of mortality. For this reason, pGSN levels have been considered as potential biomarkers of severity for several acute and chronic diseases, ${ }^{7}$ In addition, as might be predicted, systemic treatment ..." (Reference 7 is a remarkably complete review of published studies of gelsolin and should be read by anyone reading this paper.)

Page 3, right column, paragraph 2, lines 1-2 - These lines could be rewritten: "Regarding the treatment of the severe pneumonia often seen in fatal influenza, administration of rhu-pGSN ..."

Results, page 5, right column, paragraph 2, lines 12-15 - These lines could be rewritten: “...The only exception was found in trials 15-19 (Table 1) that tested dose regimens that were initially low (>2 mg rhu-pGSN on days 3 to 5/6, then $5 \mathrm{mg}$ daily through day 11). These trials led to weights (compared to day 0 ) at the ..." By including "(compared to day 0 )", it is not entirely clear whether the weights mentioned in lines 16 and 17 (81.4 and $85 \mathrm{~g}$ ?) are mean weight differences between day 0 and the end of the study in each of the two groups or the mean weight difference between the two groups at the end of the study. I assume it is the former, but the reader would have to check Extended data to be certain.

Page 5, paragraph 2, line 19 and paragraph 3, line 2 - What is the difference (if any) between 
Extended data and Underlying data? Should Underlying data really be Extended data?

Page 5, paragraph 3, line 5 - This sentence could be rewritten: “... Comparison of lung samples obtained on day 7 from vehicle-treated and rhu-pGSN-treated mice showed ..."

“Page 5, paragraph 3, lines 10-1 - This sentence could be rewritten: “... Among down-regulated genes in the rhu-pGSN-treated group, many cytokine and immune-related genes were prominent, including IL-10, IL-12b, ..."

Page 7, left column paragraph 1, line 3 - Do the "main findings" in the analysis of downregulated genes refer to all down-regulated genes or only the top 50? I assume it is the latter, but this should be made clear to the reader.

Page 7, left column, paragraph one, last four lines (and top two lines in the right column) This is a very long sentence. It's worth considering a rewrite: “...In worksheets 2-15 in the spreadsheet in Extended data, we present details of the ..."

Page 8, right column, paragraph 1, line 2 - It should be "virus stock", not "viral stock".

The authors should be commended for admitting they can't explain all of their results.

Page 8, right column, paragraph 1- The authors showed rhu-pGSN treatment offered "only a partial (albeit significant) survival benefit". Among their suggestions for future studies they mention using larger animals and other strains of influenza virus. They overlook the possibility of combining rhu-pGSN with other drug treatments. After all, they showed only a modest increase in survival (roughly $40 \%$ in vehicle-treated and $60 \%$ in rhu-pGSN-treated mice, respectively).

Combination treatment might offer a greater survival benefit. The authors might also emphasize that studies of the effects of gelsolin and treatment with rhu-pGSN on host responses to several infections suggest rhu-pGSN might used in the syndromic treatment of many different infectious diseases.

\section{References}

In addition to the two articles on gelsolin and endothelial dysfunction mentioned earlier, the authors might include their more recently published paper:

Self WH, Wunderink RG, DiNubile MJ, Stossel TP, Levinson SL, Williams DJ, et al. Low admission plasma gelsolin concentrations identify community-acquired pneumonia patients at high risk for severe outcomes. Clin Infect Dis2019; 69(7):1218-25³.

\section{Tables and Figures}

Table 1. Dividing the table into two sections showing results of treatments started on day 3 and day 6 might make it easier for readers to see the important findings. The two sets of findings could be further subdivided into those showing benefit (YES) or not (NO).

Figure 1 - The legends within panels $A, C, E$, and G show pGSH above vehicle, while in panels $B, D$, $\mathrm{F}$, and $\mathrm{H}$ the two legends are reversed. It would be better if a consistent style could be used 
throughout the figure. If the legends are changed, the authors should use rhu-pGSN, which is what they used in their studies (not pGSN).

Figure 2. - It would be helpful to include headings (down-regulated and up-regulated) at the top of the two sets of heat maps.

\section{References}

1. Becker PM, Kazi AA, Wadgaonkar R, Pearse DB, et al.: Pulmonary vascular permeability and ischemic injury in gelsolin-deficient mice.Am J Respir Cell Mol Biol. 2003; 28 (4): 478-84 PubMed Abstract | Publisher Full Text

2. Kuhne W, Besselmann M, Noll T, Muhs A, et al.: Disintegration of cytoskeletal structure of actin filaments in energy-depleted endothelial cells.Am J Physiol. 1993; 264 (5 Pt 2): H1599-608 PubMed Abstract | Publisher Full Text

3. Self WH, Wunderink RG, DiNubile MJ, Stossel TP, et al.: Low Admission Plasma Gelsolin Concentrations Identify Community-acquired Pneumonia Patients at High Risk for Severe Outcomes.Clin Infect Dis. 2019; 69 (7): 1218-1225 PubMed Abstract | Publisher Full Text

Is the work clearly and accurately presented and does it cite the current literature? Yes

Is the study design appropriate and is the work technically sound?

Yes

Are sufficient details of methods and analysis provided to allow replication by others? Yes

If applicable, is the statistical analysis and its interpretation appropriate? Yes

Are all the source data underlying the results available to ensure full reproducibility? Yes

Are the conclusions drawn adequately supported by the results? Yes

Competing Interests: No competing interests were disclosed.

Reviewer Expertise: I am a retired academic general internist with an interest in how to treat the host response to infection.

I confirm that I have read this submission and believe that I have an appropriate level of expertise to confirm that it is of an acceptable scientific standard.

Author Response 17 Feb 2020

Lester Kobzik, Harvard T.H. Chan School of Public Health, Boston, USA 
Response to Reviewer \#2:

This straightforward paper presents the results of a study showing that rhu-pGSN improves survival in a mouse model of influenza. My answers to the mandatory questions above indicate the paper is acceptable and requires no significant modification. The comments below are suggestions and are offered in the hope they might help readers. The authors should feel free to ignore them if they wish.

We are grateful for the many constructive comments and suggestions. As allowed by the reviewer, we have left some comments regarding minor layout and sentence construction issues unanswered. However, for the majority we undertook revisions in the manuscript that are reported below:

Page 3, left column, paragraph 4, lines 1-7 - The first 7 lines could be written more tightly. "One of pGSN's many functions is to dissolve the actin gels that arise from cellular debris, hence its name. These gels form a biofilm that reduces the ability of cellular and humoral defences to gain access to embedded pathogenic organisms. In response, $p G S N$ accumulates at sites of tissue damage. Interaction with actin reduces $p G S N$ 's binding to ..."

This suggested text has been used in its entirety to replace the prior version.

Page 5, paragraph 2, line 19 and paragraph 3, line 2 - What is the difference (if any) between Extended data and Underlying data? Should Underlying data really be Extended data?

These are rubrics used by F1000 and we followed editorial guidelines in designated data for one or the other grouping. The links to the data at the end of the paper allow the reader to see these data. We cannot better explain the rationale for 'underlying vs extended".

Page 5, paragraph 3, line 5 - This sentence could be rewritten: “... Comparison of lung samples obtained on day 7 from vehicle-treated and rhu-pGSN-treated mice showed ..."

This suggested text has been used in its entirety to replace the prior version.

Page 7, left column paragraph 1, line 3 - Do the "main findings" in the analysis of downregulated genes refer to all down-regulated genes or only the top 50? I assume it is the latter, but this should be made clear to the reader.

As suggested, we have clarified this point by changing the text as below to indicate that all the down-regulated genes were used for this analysis:

We performed gene enrichment analysis of the full down-regulated gene list

Page 8, right column, paragraph 1, line 2 - It should be "virus stock", not "viral stock". 
Fixed as suggested.

Page 8, right column, paragraph 1- The authors showed rhu-pGSN treatment offered "only a partial (albeit significant) survival benefit". Among their suggestions for future studies they mention using larger animals and other strains of influenza virus. They overlook the possibility of combining rhu-pGSN with other drug treatments. After all, they showed only a modest increase in survival (roughly $40 \%$ in vehicle-treated and $60 \%$ in rhu-pGSN-treated mice, respectively). Combination treatment might offer a greater survival benefit.

We have added the sentence below to this section to include this helpful idea.

We can also speculate that combination therapy with other agents might offer a greater survival advantage.

Unrelated to any specific reviewer comment, we added more detailed mention early in the Discussion of why we did not test rhu-pGSN treatment before day 3:

In addition to the impractically of initiating earlier therapy right after infection (as opposed to the onset of severe symptoms) in patients, we did not want to interfere with the immediate immune response to influenza given the detrimental consequences observed in some experimental models.

Competing Interests: No competing interests were disclosed.

Reviewer Report 18 November 2019

https://doi.org/10.5256/f1000research.23201.r56255

(C) 2019 Dockrell D. This is an open access peer review report distributed under the terms of the Creative Commons Attribution License, which permits unrestricted use, distribution, and reproduction in any medium, provided the original work is properly cited.

\section{David H. Dockrell}

MRC Centre for Inflammation Research, University of Edinburgh, Edinburgh, UK

Yang et al. explore the potential for of recombinant human gelsolin as a therapeutic intervention in a PR8 H1N1 mouse flu model. They use CD1 mice and use a variety of doses and dosing schedules with a pooled statistical analysis to infer benefits across a range of groups despite some variability in results. Benefits were seen in terms of survival and morbidity scores but not in terms of weight loss. They went on to perform transcriptional profiling and to detect reductions in inflammatory responses and increases in responses associated with tissue repair. 
Strengths of the study are the investigation of a therapeutic approach for a potential life threatening infection and the preliminary hypothesis generating transcriptomic data set which provide clues to potential mechanisms. A few areas of the text should be addressed to strengthen the main conclusions.

The authors have had significant statistical input but some further explanation of the statistical approach and its potential benefits to a study such as this would be useful.

The study used CD1 mice which may explain some of the variability. A few further details should be added to the methods. The authors should confirm the reason for just studying males. They should confirm animals and groups were co-housed and, in a study with such large numbers, explain whether there were any majors groupings or time periods used in the study which might have contributed to variability. Were mice bought in in small groups or are the subgroups from predominantly the same larger pool bred in house? Also they should confirm the mice were infected at similar times of day.

The authors might also comment on the rationale for using human gelsolin. Some differences in response between human and mouse gelsolin have been detected and the authors might wish to comment on this and their similarities and differences.

The authors did not find any major differences in weight. Can the authors comment further on this since this is usually a marker of outcome. In addition the mortality curves appeared to be still showing deaths at the end of the study period. Can the authors confirm that the main biologic affect was a delay in mortality rather than prevention? Clarifying this in the text would resolve any uncertainty relating to the conclusion and title.

The transcriptomic data is of interest. Can the authors drill down further and confirm any subgroupings related to inflammation or tissue repair? In particular is their any evidence of an epithelial protective affect such as enhancement of barrier function or epithelial apoptosis inhibition, since this is potentially one of gelsolins biologic functions. I assume there is no additional data from BAL cytokines, cell counts or histology to back up the transcriptomics but if there are any further data, they would strengthen the conclusions.

\section{Is the work clearly and accurately presented and does it cite the current literature?} Yes

Is the study design appropriate and is the work technically sound? Yes

Are sufficient details of methods and analysis provided to allow replication by others? Partly

If applicable, is the statistical analysis and its interpretation appropriate? Yes

Are all the source data underlying the results available to ensure full reproducibility? 
Yes

Are the conclusions drawn adequately supported by the results?

Partly

Competing Interests: No competing interests were disclosed.

Reviewer Expertise: Pathogeneiss of infectious diseases, especially respiratory tract infections.

I confirm that I have read this submission and believe that I have an appropriate level of expertise to confirm that it is of an acceptable scientific standard.

Author Response 17 Feb 2020

Lester Kobzik, Harvard T.H. Chan School of Public Health, Boston, USA

Response to Reviewer \#1:

The study used CD1 mice which may explain some of the variability. A few further details should be added to the methods.

The authors should confirm the reason for just studying males.

They should confirm animals and groups were co-housed and, in a study with such large numbers, explain whether there were any majors groupings or time periods used in the study which might have contributed to variability. Were mice bought in in small groups or are the subgroups from predominantly the same larger pool bred in house?

Also they should confirm the mice were infected at similar times of day.

To address these points, the following text has been inserted into the methods:

Only male mice were used due to budgetary and time limits. All mice arrived and were cohoused 1 week prior to the start of the experiments. Each trial used a separate batch of mice.

All infections were done at approximately the same time of day (starting at 10 AM).

The authors might also comment on the rationale for using human gelsolin. Some differences in response between human and mouse gelsolin have been detected and the authors might wish to comment on this and their similarities and differences.

To address this comment, the following text has been inserted into the methods:

We used human rather than murine gelsolin based on prior demonstrations of function of rhu-pGSN in rodent models and because data with the human gelsolin will facilitate clinical translation efforts.

The authors did not find any major differences in weight. Can the authors comment further on 
this since this is usually a marker of outcome. In addition the mortality curves appeared to be still showing deaths at the end of the study period. Can the authors confirm that the main biologic affect was a delay in mortality rather than prevention? Clarifying this in the text would resolve any uncertainty relating to the conclusion and title.

We were also puzzled by the lack of weight differences but have no explanation to offer. A small number of the initial trials followed mice longer than the period reported in the paper. Mice surviving to day 12 continued to live up to day 18-21 in these early trials. However, this was not systematically studied so it is fair to say it is a qualitative impression rather than a quantitative result. Extending the trial length would require additional experimentation. Either a significant delay in mortality or true improved survival would provide the same basis for supporting further studies of rhu-pGSN as a therapeutic worth validating in other models (e.g. ferret).

Re: the reviewer's point about mortality, we now explicitly acknowledge in the Discussion: Mice were only followed for 12 days when euthanasia was performed on surviving mice. Since the survival curves were still potentially declining, the ultimate mortality rate could not be confidently ascertained. However, the time to death at a minimum was prolonged with rhu-pGSN over placebo treatment.

The transcriptomic data is of interest. Can the authors drill down further and confirm any subgroupings related to inflammation or tissue repair? In particular is their any evidence of an epithelial protective affect such as enhancement of barrier function or epithelial apoptosis inhibition, since this is potentially one of gelsolins biologic functions. I assume there is no additional data from BAL cytokines, cell counts or histology to back up the transcriptomics but if there are any further data, they would strengthen the conclusions.

We did not find any enrichment for the groupings suggested beyond what we reported in the supplemental data spreadsheet. No additional data from the samples listed by the reviewer is available are available, so this interesting topic can only be addressed in future studies. A comment on treatment changes between the two time points for transcriptome profiling was inserted in the Results section:

Per protocol, the rhu-pGSN dose was increased in this experiment on day 7 , between the 2 timepoints selected for profiling.

Competing Interests: No competing interests were disclosed.

\section{Comments on this article}

\section{Version 2}




\section{Author Response 25 Mar 2020}

Mark DiNubile, BioAegis Therapeutics, North Brunswick, USA

SARS-CoV-2 causes fatal infections by eliciting an over-exuberant immune response leading to injurious lung inflammation +/- a cytokine storm. Patients may die from ARDS or survive with debilitating pulmonary fibrosis. Interventions like hydroxychloroquine and azithromycin have been proposed as treatment modalities to modulate the intense host reaction and potentially improve respiratory outcomes independent of a direct antiviral effect.

Plasma gelsolin (pGSN, an abundant, naturally-occurring, circulating protein depleted in severe inflammatory conditions) offers similar promise in aborting lung injury, and should be treated as a possible novel therapeutic agent in this time of crisis. The recombinant human form (rhu-pGSN) has already been given safely to patients with mild community-acquired pneumonia (CAP).

Since rhu-pGSN is a pathogen-indifferent Rx acting on host inflammatory responses, the microbial etiology of life-threatening CAP is not particularly relevant. We hope our product will be reviewed quickly in this light.

Mark J. DiNubile, MD

CMO, BioAegis Therapeutics

6097065866

Competing Interests: I am a co-author of the article in question and the CMO of the company developing rhu-pGSN for clinical use.

The benefits of publishing with F1000Research:

- Your article is published within days, with no editorial bias

- You can publish traditional articles, null/negative results, case reports, data notes and more

- The peer review process is transparent and collaborative

- Your article is indexed in PubMed after passing peer review

- Dedicated customer support at every stage

For pre-submission enquiries, contact research@f1000.com 